\title{
The Culture of Bordetella pertussis
}

\author{
By L. B. HOLT \\ The Wright-Fleming Institute, St Mary's Hospital Medical School, \\ London, W. 2
}

(Received 7 July 1961)

SUMMARY

Bordetella pertussis grew profusely and retained its normal minute coccobacillary form when grown under $0.4 \mathrm{~mm}$. of fluid lying on a Cohen \& Wheeler agar medium + charcoal. Microbes grown in this way were fully antigenic in terms of the mouse protection test. It was easy to obtain harvests of $1.2 \times 10^{11}$ organisms $/ \mathrm{ml}$.

\section{INTRODUCTION}

Apart from the classical work of Bordet and the introduction of the BordetGengou medium for Bordetella pertussis, the most important observations concerning the growth conditions for this organism would seem to be those made by Pollock (1949) who demonstrated the growth-inhibitory effect of small quantities of unsaturated fatty acids in the medium. The incorporation of powdered charcoal, by Powell, Culbertson \& Ensminger (1951), in agar-solidified Cohen \& Wheeler (1946) medium presumably aids growth by absorbing such lipid inhibitors. The first modification to the Cohen $\&$ Wheeler agar medium + charcoal made in these laboratories was the substitution of washed granular charcoal $(0.5 \%, w / v$, British Drug Houses Ltd. for gas adsorption) for the powdered charcoal. This modification yielded a charcoal-free white vaccine. The second modification arose from the observation that, when the volume of implant was excessive and the surface of the agar medium not truly horizontal, the growth of the organism was very poor where the medium surface was relatively drier than elsewhere, and also where the depth of fluid was excessive, but that there was an intermediate narrow zone of heavy growth where the surface was thinly covered with fluid. This observation was investigated.

\section{METHODS}

A setting table and the incubator shelves were adjusted to be truly horizontal. Flat 1-l. bottles containing $100 \mathrm{ml}$. of the agar medium were used, giving $200 \mathrm{sq} . \mathrm{cm}$. of surface and $0.5 \mathrm{~cm}$. depth of medium. Several of these bottles were seeded with different volumes of implant, of the same count, ranging from 5 to $20 \mathrm{ml}$./bottle and the agar surfaces were completely covered. Counts were made by opacity using the N.I.H. Standard Opacity tube, and antigenic potency by using the mouse intracerebral challenge method (W.H.O. Tech. Rep. Series, no. 61). 


\section{RESULTS}

The harvest after growth on the above medium at $34^{\circ}$ for 3 days from the 5 and $10 \mathrm{ml} . / 200 \mathrm{sq} . \mathrm{cm}$. of surface was $4.5 \times 10^{10}$ organisms $/ \mathrm{ml}$. medium, compared with $3.6 \times 10^{10}$ from the $15 \mathrm{ml}$. implant and $2.7 \times 10^{10}$ from the $20 \mathrm{ml}$. implant. The volume chosen for routine use was $8 \mathrm{ml} . / 200 \mathrm{sq} . \mathrm{cm}$. of surface, giving a depth of fluid on the medium of $0.4 \mathrm{~mm}$. Different strains of Bordetella pertussis differed in the yield given on this medium when grown in this way. The harvest, however, was rarely less than $3 \times 10^{10}$ organisms $/ \mathrm{ml}$. medium, which means that when the culture was collected in $20-25 \mathrm{ml}$. saline the count (by opacity) was about $1 \cdot 2 \times 10^{11}$ organisms $/ \mathrm{ml}$. The same agar base could be used three times by adding to the agar residue (after harvesting) $10 \mathrm{ml}$. of $10 \%(\mathrm{w} / \mathrm{v})$ neutralized Casamino acids and re-incubating. This could be done on two successive occasions.

The organisms when grown in this way were extremely small and capsulated; large and filamentous forms were rare. Large and filamentous forms did appear, although not in large numbers, when the depth of fluid was too great, or when the yeast extract diffusate was omitted from the medium. In contrast to this it was found that when the same medium was used in Petri dishes, with a dry surface, growth was much slower than on a control Bordet-Gengou plate. After 3 days of incubation no colonies were visible on the Cohen \& Wheeler (1946) medium + charcoal although well developed on the Bordet-Gengou plate. After a further 5 days of incubation, however, the same number of colonies were present on the Cohen \& Wheeler medium + charcoal plates as were on the Bordet-Gengou plates for the same size of implant. Vaccines prepared from our selected strains grown in this modified Cohen \& Wheeler agar medium + charcoal had an antigenic potency (by mouse intracerebral challenge), significantly greater than the British Standard pertussis vaccine, and agglutinated to 1/500 using Standard Bordetella pertussis Agglutinating Serum (Public Health Laboratory Service, Colindale). Apart from the ease of preparation of the medium, an important advantage of the method is that the cultures can be grown and harvested without mechanical aids (e.g. shakers for culture or centrifugation of crops).

\section{DISCUSSION}

The reason for the success of the technique described is thought to be that the inhibitors left in the medium normally concentrate at the agar surface in the form of soaps and free fatty acids and are therefore at their greatest concentration exactly where the implant is made. By covering the agar surface with a film of fluid, the inhibitors are transferred to the upper surface of the fluid, and the microbes are able to grow away from them, at the agar/fluid interface. And because Bordetella pertussis is an obligate aerobe, the thickness of the fluid film is critical. The ease with which $B$. pertussis grows when planted away from a free surface in the above way, the fact that the same agar base may be used three times and that the yeast extract diffusate may be omitted from the medium would together seem to indicate that the microbe has no essential growth factor requirements. Nevertheless, since it was found that the omission of yeast-extract diffusate, or too deep a film of fluid on the agar base, gave rise to the rapid appearance of large and filamentous forms, it would seem that a factor is required for normal growth under conditions of lowered oxygen tension. 
The relative slowness of growth on the Cohen \& Wheeler charcoal agar + charcoal medium as compared with that on a Bordet-Gengou plate, or when the base is covered by a thin film of fluid, would seem to indicate that the inhibitors in the medium act solely by increasing the mean generation time of the organism.

\section{REFERENCES}

Cohen, S. M. \& Wheeler, M. W. (1946). Pertussis vaccine prepared with Phase-I cultures grown in fluid medium. Amer. J. publ. Hlth, 36, 371.

PoLLock, M. R. (1949). The effects of long-chain fatty acids on the growth of Haemophilus pertussis and other organisms. Symp. Soc. exp. Biol. 3, 193.

Powell, H. M., Culbertson, C. G. \& Ensminger, P. W. (1951). Charcoal agar culture medium for preparing Haemophilus pertussis vaccine. Publ. Hlth Rep., Wash. 66, 346. 